\title{
IMPLEMENTASI ALGORITMA HILL CLIMBING PADA PENENTUAN JARAK TERPENDEK KOTA WISATA DI INDONESIA
}

\author{
Desti Fitriati $^{1}$, Nura Meutia Nessrayasa ${ }^{2}$ \\ ${ }^{1}$ Teknik Informatika \\ Fakultas Teknik, Universitas Pancasila \\ desti.fitriati@univpancasila.ac.id \\ ${ }^{2}$ Teknik Informatika \\ Fakultas Teknik, Universitas Pancasila \\ nurameutia@gmail.com
}

\begin{abstract}
Abstrak
Pencarian dan penentuan rute terpendek merupakan masalah yang rumit, mencari rute terpendek dari sejumlah objek wisata dan jarak antar objek wisata. Dengan akses jalur yang bervariasi, pencarian rute terpendek menjadi pilihan yang tepat menggunakan sebuah aplikasi berbasis website yang memberikan rute terdekat pada sebuah peta dengan menggunakan algoritma SAHC (Steepest Ascent Hill Climbing). Steepest Ascent Hill Climbing merupakan metode algoritma yang banyak digunakan untuk permasalahan optimasi. Salah satu penerapannya adalah untuk mencari rute yang terpendek dengan cara memaksimumkan atau meminimumkan nilai dari fungsi optimasi yang ada. Dalam penelitian ii penelitian mengunakan 34 propinsi di Indonesia dan setiap propinsi terdapat 5 wisata terpopuler, nilai akurasi yang diperoleh dalam penelitian penentuan jarak terpendek kota wisata di Indonesia adalah 93,3 \%
\end{abstract}

Kata kunci: Jarak Terpendek, wisata, Steepest Ascent Hill Climbing

\begin{abstract}
Searching and determining the shortest route is a complex problem, looking for the shortest route from a number of attractions and the distance between attractions. With varying access paths, the shortest route search becomes the right choice using a website-based app that provides the closest route on a map using the SAHC (Steepest Ascent Hill Climbing) algorithm. Steepest Ascent Hill Climbing is a method of algorithm that is widely used for optimization problems. One application is to find the shortest route by maximizing or minimizing the value of the existing optimization function. In research ii study using 34 provinces in Indonesia and every province there are 5 most popular tour, accuracy value obtained in research determination of shortest distance of tourist city in Indonesia is 93,3\%.
\end{abstract}

Keywords: Shortest Distance, Tour, Steepest Ascent Hill Climbing

\section{PENDAHULUAN}

Menurut Menteri Pariwisata Arief Yayha yang dikutip oleh harian cnnindonesia.com, Indonesia merupakan negara yang sektor pariwisatanya dapat meningkatkan perekonomian dan unggul dibandingkan negara-negara lain di Asia Tenggara. Sektor pariwisata memang menjadi salah satu sektor andalan negara ini. Dari data yang diperoleh World Economic Forum (WEF) berdasarkan Travel \& Tourism Competitiveness Index 2015, Indonesia ternyata mengalami peningkatan, Indonesia menempati peringkat 50 sebagai negara dengan tingkat pariwisata yang kompetatif. Hal tersebut di dorong dengan terus meningkatnya tujuan wisata yang menyebar di seluruh provinsi Indonesia, Sehingga mampu menarik kunjungan wisatawan domestik maupun asing selain itu hal tersebut mampu menghipnotis setiap mata yang berkunjung ke seluruh tempat wisata di Indonesia, Banyak para wisatawan menginginkan jalur yang efisien untuk mencapai tempat tujuan wisata. Wisatawan tersebut ingin mengunjungi salah satu atau beberapa tempat wisata sekaligus dalam waktu singkat dan jarak yang terpendek. Akan tetapi banyak dari wisatawan tersebut tidak mengetahui jalur tempat wisata yang efisien untuk menunju tempat wisata yang akan di tuju, Sehingga menghabiskan banyak waktu di perjalanan dan tidak efektif (Tjahjono, 2010). 
Dari masalah yang telah diuraikan sebelumnya, dibutuhkan sebuah solusi untuk pencarian rute terpendek. Pencarian suatu rute perjalanan yang singkat merupakan salah satu hal penting, karena dengan adanya perencanaan jalur perjalanan sebelumnya akan memberikan kemudahan dalam menentukan jalur yang akan ditempuh dengan jarak terpendek sehingga waktu, tenaga, dan biaya menjadi lebih hemat.

Pencarian dan penentuan rute terpendek merupakan masalah yang rumit (Belalawe, Suyanto, \& Sofyan, 2015), mencari rute terpendek dari sejumlah objek wisata dan jarak antar objek wisata yang harus dilalui oleh wisatawan yang berangkat dari titik A dan berhenti di tempat objek wisata di titik B melanjutkan perjalananannya ke tempat objek wisata di titik $C$ dan kembali lagi ke titik A. Dengan akses jalur yang bervariasi, pencarian rute terpendek menjadi pilihan yang tepat. Oleh karena itu, agar tujuan sistem dapat tercapai maka perlu didukung dengan menggunakan salah satu algorima dalam penentuan rute terpendek. Terdapat banyak algoritma yang digunakan untuk menentukan jalur terpendek salah satunya adalah hill climbing. Algoritma Hill Climbing sering digunakan jika terdapat fungsi heuristic yang baik untuk mengevaluasi state (Sihombing, 2014). Berdasarkan referensi dari berberapa penelitian yang telah mencoba untuk mengimplentasikan algoritma ini diantaranya adalah penelitian yang dilakukan oleh Rakhman Gusti Subehi, Dini Nurmala Sari dan Heni Rachmawati menyimpulkan bahwa algoritma Hill Climbing dapat menghasilkan penentuan jalur terpendek. Sehingga para wisatawan akan mendapatkan rute tercepat dengan posisi yang akurat. Dengan memanfaatkan algoritma hill climbing akan diketahui rute terpendek beberapa objek wisata yang akan dikunjungi di Indonesia sehingga dapat membantu wisatawan dalam memilih tempat wisata.

\section{METODOLOGI PENELITIAN}

\section{A. Travelling Salesman Problem}

Traveling Salesman Problem (TSP) secara umum merupakan masalah optimasi yang Kompleks, sebagai pencarian urutan semua lokasi (misalnya kota) yang harus dikunjungi, bagaimana menentukan jarak terpendek dalam perjalanan melewati titik-titik tertentu. Setiap kota hanya diperbolehkan untuk dikunjungi satu kali (Suyanto, 2014). TSP dikemukakan pada tahun 1800 oleh William Rowan Hamilton dan Thomas Penyngton $\mathrm{K}$, sedangkan bentuk umum TSP pertama dipelajari oleh matematikawan pada tahun 1930. Secara umum TSP dibedakan menjadi dua bentuk yaitu TSP Simetris dan TSP Asimetris. Langkah pertama dalam menyelesaikan Traveling Salesman Problem adalah dengan menggunakan formula matematika dengan graph sebagai strukturnya, di mana setiap kota dinotasikan dengan sebuah node dan jarak antar kota digambarkan dengan garis (arcs atau edges). Kemudian panjang dari sebuah perjalanan merupakan hasil penjumlahan dari jarak antar kota-kota yang dilalui. TSP merupakan sekumpulan kota dan biaya perjalanan (atau jarak) yang diberikan antar masing-masing pasangan kota yang digunakan untuk menemukan jalan terbaik kunjungan ke semua kota dan kembali ke titik awal dalam upaya meminimalkan biaya atau jarak perjalanan (Davendra, 2010).

\section{B. Pencarian Heuristik}

Heuristik adalah sebuah teknik yang mengembangkan efisiensi dalam proses pencarian, namum dengan kemungkinan mengorbankan kelengkapan (completeness). Untuk mengukur performansi metode pencarian, terdapat empat kriteria yang dapat digunakan (Coppin, 2004):

1. Completeness : apakah metode tersebut menjamin penemuan solusi jika solusinya memang ada;

2. Time complexity : berapa lama waktu yang diperlukan;

3. Space complexity : berapa banyak memori yang diperlukan;

4. Optimality : apakah metode tersebut menjamin menemukan solusi yang terbaik jika terdapat beberapa solusi berbeda.

\section{Metode Hill Climbing Search}

Hill Climbing sering digunakan jika terdapat suatu fungsi heuristic yang baik untuk mengevaluasi state (Suyanto, 2014). Hill Climbing adalah proses pengujian yang dilakukan dengan menggunakan fungsi heuristik. Cara kerjanya adalah menentukan langkah berikutnya dan menempatkan node yang akan muncul sedekat mungkin dengan sasarannya atau langkah selanjutnya. Hill climbing adalah teknik optimasi menemukan pemecahan masalah dari data yang input dengan menggunakan algoritma. Algoritma tersebut tidak mempertahankan pohon pencaharian namun hanya dapat melihat pada kondisi saat ini, dan state yang akan datang. Metode Hill Climbing Search ini terbagi menjadi 2 
(dua) yaitu Simple Hill Climbing dan Steepestascent Hill Climbing (Kusumadewi, 2003):

\section{Simple Hill Climbing}

Simple Hill Climbing menggunakan fungsi heuristik (fx) yang akan memberikan suatu perkiraan ukuran jarak tujuan dari node x. Teknik Hill Climbing dapat digunakan untuk memecahkan persoalan yang memiliki banyak alternatif solusi untuk kemudian memilih solusi yang terbaik.

Algoritma untuk Hill Climbing Search adalah sebagai berikut :

- Mulai dari keadaan awal, lakukan pengujian: jika merupakan tujuan, maka berhenti; dan jika tidak, lanjutkan dengan keadaan sekarang sebagai keadaan awal.

- Kerjakan langkah-langkah berikut sampai solusinya ditemukan, atau sampai tidak ada node baru yang akan diaplikasikan pada keadaan sekarang :

- Cari node yang belum pernah digunakan; gunakan node ini untuk mendapatkan keadaan yang baru.

Evaluasi keadaan baru tersebut.

- Jika keadaan baru merupakan tujuan, keluar.

- Jika bukan tujuan, namun nilainya lebih baik daripada keadaan sekarang, maka jadikan keadaan baru tersebut menjadi keadaan sekarang.

- Jika keadaan baru tidak lebih baik daripada keadaan sekarang, maka lanjutkan pencarian.

\section{Steepest Ascent Hill Climbing Search}

Steepest-Ascent Hill Climbing Search hampir sama dengan Simple Hill Climbing Search dan yang membedakan keduanya adalah pada gerakan pencarian yang tidak dimulai dari posisi paling kiri. Gerakan berikutnya dicari berdasarkan nilai heuristik terbaik. Dalam hal ini urutan penggunaan tidak menentukan penemuan solusi (Kusumadewi, 2003). Algoritma untuk SteepestAscent Hill Climbing Search adalah :

- Mulai dari keadaan awal, lakukan pengujian. Jika merupakan tujuan maka berhenti, dan jika tidak, lanjutkan dengan keadaan sekarang sebagai keadaan awal.

- Ulangi hingga tujuan tercapai atau hingga pencarian tidak memberikan perubahan pada keadaan sekarang.

- Tentukan SUCC sebagai nilai heuristik dari successor-successor.

- Lakukan untuk tiap node yang digunakan oleh keadaan sekarang.

- Gunakan node tersebut dan bentuk keadaan baru.
Evaluasi keadaan baru tersebut jika merupakan tujuan keluar. Jika bukan, bandingkan nilai keuristiknya dengan SUCC.

- Jika lebih baik, jadikan nilai heuristik keadaan batu tersebut sebagai SUCC, tetapi jika tidak lebih baik, nilai SUCC tidak berubah.

- Jika SUCC lebih baik daripada nilai heuristik keadaan sekarang, ubah node SUCC menjadi keadaan sekarang.

\section{Analisis Algoritma Steepest-Ascent Hill Climbing}

Algoritma Steepest Ascent Hill Climbing (SAHC) adalah algoritma yang menggunakan estimasi jarak terdekat (cost / jarak sebenarnya) untuk mencapai tujuan (goal).

Algoritma SAHC (Steepest Ascent Hill Climbing) hampir sama dengan algoritma simple hill climbing, yang membedakan keduanya adalah pada pencarian atau pertukaran kombinasi tiap node yang bila menemukan satu node tidak langsung berhenti tetapi dilanjutkan dengan mencari apakah ada node lain yang memiliki nilai heuristik yang lebih baik. Berikut ini adalah gambar proses penyelesaian solusi dengan menggunakan Algoritma SAHC (Steepest Ascent Hill Climbing).

\section{E. Tahap Pengumpulan Data}

Metode pengumpulan data yang digunakan dalam penelitian ini adalah metode studi literatur. Metode ini dimaksudkan untuk mempelajari literatur berupa referensi jurnal yang sudah terpercaya keaslian datanya dengan konsep dan teori dasar mengenai metode Algoritma Hill Climbig baik Simple Hill Climbing maupun Steepest Ascent Hill Climbing, data mengenai tempat wisata popular di Indonesia, dan sebagainya yang digunakan untuk mendukung pembuatan sistem ini dan juga sebagai penunjang penelitian agar tidak menyimpang dari kondisi yang ada.

\section{F. Tahap Pengolahan Data}

Metode penelitian sangat diperlukan untuk memperoleh data yang tepat dan akurat diantaranya adalah :

1. Steepest Ascent Hill Climbing.

Steepest Ascent Hill Climbing melakukan pencarian berdasarkan nilai heuristic terbaik. Penggunan operator tidak menentukan penemuan solusi, salah satu penerapannya untuk mencari rute yang terpendek dengan cara 
memaksimumkan atau meminimumkan nilai fungsi optimasi yang ada.

Metode Steepest Ascent Hill Climbing ini merupakan pengembangan dari metode simple hill climbing, steepest ascent hill climbing akan membandingkan current state dengan semua succesors yang ada didekatnya sehingga next statenya merupakan successor yang paling baik atau paling mendekati tujuan.

\section{Langkah-langkah :}

Menentukan kombinasi Operator yang digunakan adalah dengan menukar urutan posisi 2 node yang berada dalam suatu lintasan. Apabila ada $n$, dan ingin mencari kombinasi lintasan dengan menukar posisi urutan 2 node, maka akan mendapatkan sebanyak. Mencari kombinasi dengan rumus :

$\mathrm{C}=\mathrm{n} ! / 2 !(\mathrm{n}-2) !$

Keterangan :

C : Kombinasi

(n) : Jumlah data

(n!) : Jumlah dengan data di faktorialkan

\section{HASIL PENELITIAN DAN PEMBAHASAN}

Berikut ini adalah implementasi output dari penerapan algoritma hill climbing untuk mencari jarak terpendek kota wisata di Indonesia dengan memasukkan titik awal sama dengan titik akhir dan memilih tempat wisata yang berbeda propinsi

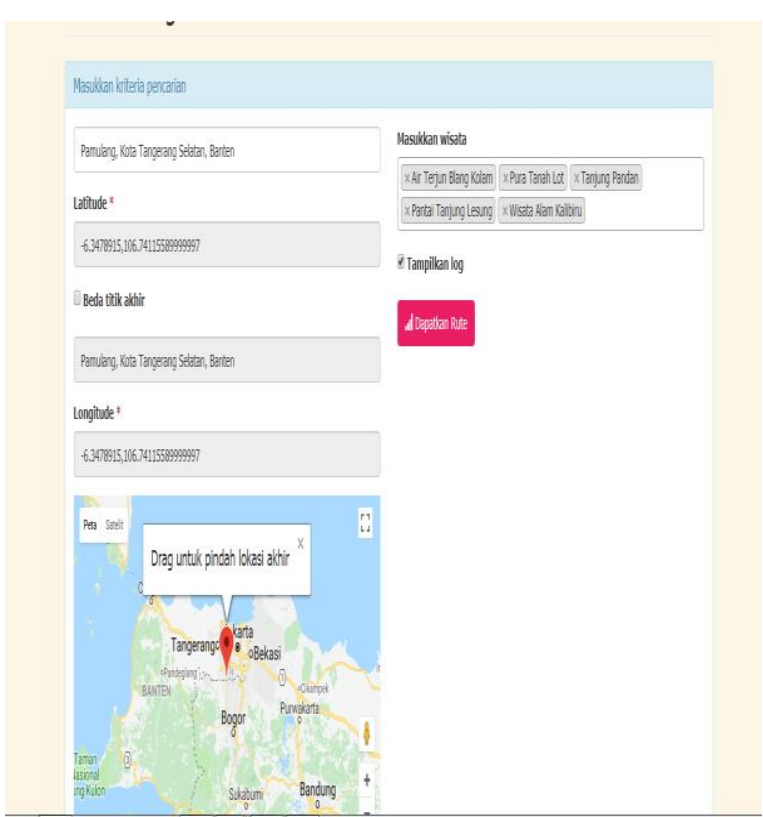

Gambar 1. Implementasi Titik Awal dan Akhir Sama
Pada Gambar 1 merupakan langkah pertama apabila user ingin menggunakan sistem tersebut yaitu dengan memasukkan titik awal (keberangkatan) dan titik akhir (tujuan akhir) dan memasukkan tempat wisata yang ingin dituju pada gambar tersebut titik awal dan akhir sama artinya user akan kembali pulang ke tempat dia berangkat.

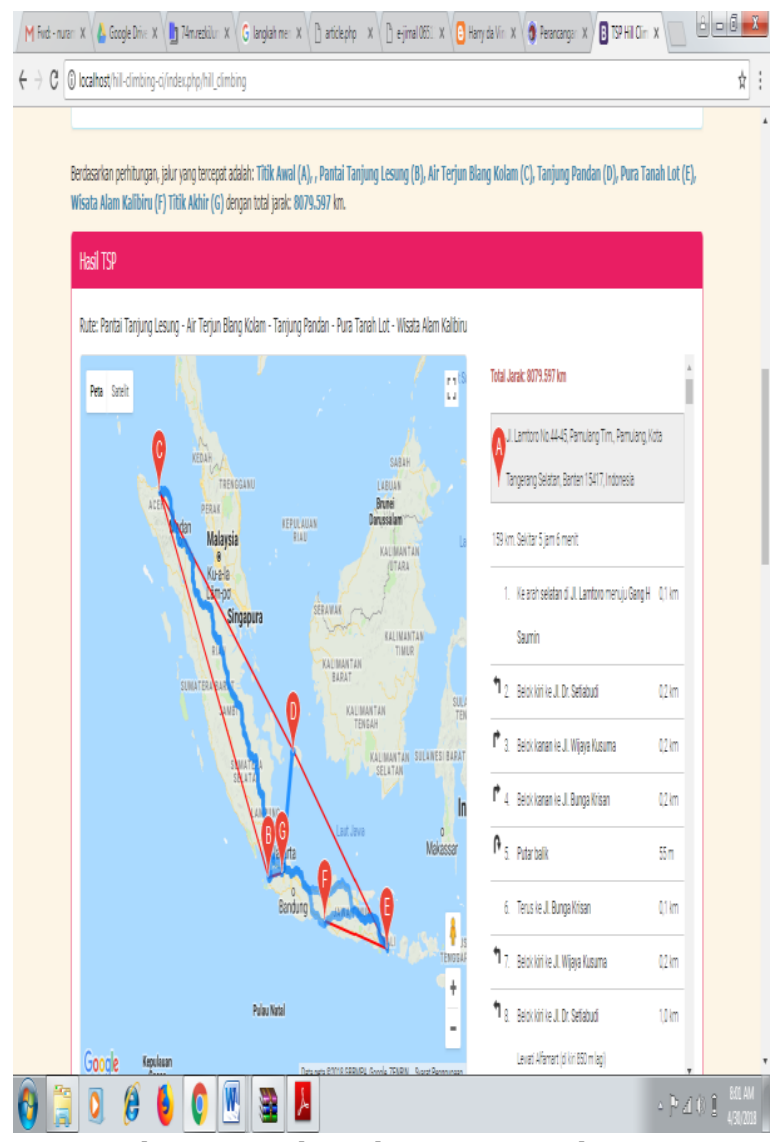

Gambar 2. Hasil Implementasi Perhitungan

Sedangkan pada gambar 2 merupakan hasil perhitungan yang dilakukan sistem dan menunjukkan rute terpendek yang dapat user tempuh untuk ketempat wisata tujuan.

Analisis yang dilakukan adalah analisis tingkat akurasi sistem. Analisis tingkat akurasi berdasarkan hasil pengujian yang telah dilakukan, jumlah seluruh data sampling adalah 30 data. maka tingkat akurasi yang dihasilkan adalah 93,3\%. Dengan rumus sebagai berikut :

$$
\begin{gathered}
\text { Akurasi }=\frac{\text { Jumlah Data Yang Benar }}{\text { Jumlah Total Data }} \times 100 \% \\
\text { Akurasi }=\frac{28}{30} x 100 \%=93,3 \%
\end{gathered}
$$




\section{SIMPULAN DAN SARAN}

\section{Simpulan}

Berdasarkan penelitian yang telah dilakukan, dapat disimpulkan bahwa Fitur-fitur pendukung seperti fungsi hill climbing sebuah sistem menggunakan algoritma Steepest Ascent Hill Climbing. Hasil Uji Akurasi dengan mengimplementasikan algoritma hill climbing diperoleh nilai akurasi sebesar 93,3\%

\section{Saran}

Saran yang bisa penulis sampaikan untuk pengembangan selanjutnya pada penelitian ini yaitu aplikasi yang telah di rancang dalam penelitian ini menggunakan algoritma SAHC (Steepest Ascent Hill Climbing) berbasis web yang masih bias di kembangkan agar berbasis Android.

\section{DAFTAR REFERENSI}

Belalawe, B. J., Suyanto, M., \& Sofyan, A. F. (2015). PENENTUAN JALUR WISATA TERPENDEK MENGGUNAKAN METODE FORWARD CHAINING (Studi Kasus Dinas Pariwisata Kota Kupang). Seminar Nasional Informatika (SEMNASIF), 1(3). Retrieved from http://jurnal.upnyk.ac.id/index.php/semnasi f/article/view/1042

Coppin, B. (2004). Artificial Intelligence Illuminated (1st ed.). Sudbury, Massachusetts: Jones \& Bartlett Learning.

Davendra, D. (2010). Traveling Salesman Problem: Theory and Applications. (T. Smiljanic, Ed.) (1st ed.). London: InTech.

Kusumadewi, S. (2003). Artificial Intelligence (Teknik dan Aplikasinya) (1st ed.). Yogyakarta: Graha Ilmu. Retrieved from http://grahailmu.co.id/previewpdf/9793289-19-8-6.pdf

Sihombing, J. (2014). Perancangan Aplikasi Pencarian Jalur Terpendek Untuk Daerah Kota Medan Dengan Metode Steepest Ascent Hill Climbing. Jurnal Pelita Informatika Budidarma, 6(2), 5-11.

Suyanto, S. (2014). Artificial Intelligence: Searching, Reasoning, Planning and Learning (1st ed.). Badung: Informatika. Retrieved from https://suyanto.staff.telkomuniversity.ac.id/ textbook-artificial-intelligence/
Tjahjono, H. (2010). ANALISIS POTENSI DAN MASALAH PARIWISATA DI KELURAHAN KANDRI. Forum Ilmu Sosial, 37(2). https://doi.org/10.15294/FIS.V37I2.1529 
